\title{
Circadian rhythms and sleep regulation in seasonal affective disorder
}

\author{
A. WIRZ-JUSTICE, K. KRÄUCHI, D.P. BRUNNER, P. GRAW, H.-J. HAUG, \\ G. LEONHARDT, A. SARRAFZADEH, J. ENGLISH* , J. ARENDT*
}

\begin{abstract}
Keywords: winter depression, constant routine, $\operatorname{mood}$, body temperature, melatonin, sleep-EEG

Sleutelwoorden: winterdepressie, constant routine, stem ming, lichaamstemperatuur, melatonine, slaap-EEG

Acta Neuropsychiatrica 1995;7:41-43
\end{abstract}

"If I may offer just one more summary.

otherwise we won't get anywhere."

Rutger Kopland
Correspondence address:

Prof. A. Wirz-Justice, Ph.D.

Psychiatric University Clinic

Wilhelm-Klein-Strasse 27

CH 4025 Basel, Switzerland

*Dept. of Biological Sciences, University of Surrey, UK.

Acknowledgements

We thank G. Moll, C. Hetsch, and Drs. C.A. Czeisler and

J. Anderson for assistance. Supported by SNF Grants the

Roche, Sandoz and Horten Foundations.

vation of the CR. Four parameters are briefly summarized here.

\section{RESULTS}

recurrent episodes in autumn and winter of depression, hypersomnia, augmented appetite with carbohydrate craving, and weight gain, and can be successfully treated with bright light. ${ }^{1}$ Circadian rhythm hypotheses (summarized in $^{2}$ ) have stimulated research into the pathophysiology of SAD, postulating that:

1. The illness is a consequence of delayed phase position, 2. It is correlated with diminished circadian amplitude, or

3. It results from changes in the nocturnal duration between dusk and dawn e.g. of low core body temperature or melatonin secretion. Light is considered to act directly on the circadian pacemaker ('Process C') and not on sleep dependent processes ('Process S'). ${ }^{3}$ Thus successful treatment of SAD must act via mechanisms within known retinohypothalamic pathways. Conversely, emergence of SAD symptoms may reflect inappropriate neurobiological response to decreasing daylength.

It is difficult to test these circadian hypotheses under normal nychthemeral conditions, due to 'masking' of the expression of the circadian pacemaker to varying degrees by activity, sleep, meals, light, and ambient temperature. If there is an underlying dysfunction of biological timing in SAD, the 'Constant Routine' (CR) protocol may be the most stringent method to uncover it. ${ }^{4}$ The $\mathrm{CR}$ consists of $40 \mathrm{~h}$ of sleep deprivation while sitting in bed under controlled photic and thermal conditions. In winter, we carried out a CR protocol in 11 women with SAD and 8 healthy controls (24-66y) during the follicular phase of their menstrual cycle (if present), before and after 5 days of 6000 lux light therapy from 10-14h. A large battery of psychological ratings, physiological and neuroendocrine measurements revealed significant circadian rhythms under unmasked conditions. Additionally, the sleep EEG was recorded before and after the controlled sleep depri-

\section{Mood follows a circadian rhythm}

Depressed SAD patients improved after the total sleep deprivation of the CR (self-rated visual analogue scales at half-hourly intervals permitted a very precise analysis of the kinetics of this sleep deprivation response). They relapsed after recovery sleep. Light therapy induced more stable improvement. Both controls and SAD patients showed a circadian rhythm of mood (Fig. 1). ${ }^{2,5}$ The 'unmasked' rhythm revealed a more complex wave form ('afternoon dip' as well as circadian trough) than prior studies of diurnal variation of mood would suggest. The afternoon dip was particularly clear on the day after sleep deprivation. The presence of a circadian rhythm in both controls and SAD patients suggests an important endogenous component to changes in affect: indeed, strong evidence for this has been obtained in the forced desynchrony protocol. ${ }^{6}$

\section{Core body temperature}

The rectal temperature rhythm is a validated marker of the circadian pacemaker ${ }^{4}$, with which the three circadian hypotheses of SAD pathophysiology can be directly tested. ${ }^{7,8}$ For characterising the rhythm of each subject, least-squares regression analysis was applied to calculate the best fit to a combined 24-h-period cosine function, its 12-h-period harmonic and a linear component. As shown in figure 2 and table I, the 'classical' marker of phase, the circadian minimum, did not significantly differ between SAD patients and controls; nor was there a difference in amplitude or duration of the nocturnal temperature minimum between the mid-range crossings. None of these parameters were modified by midday light. 

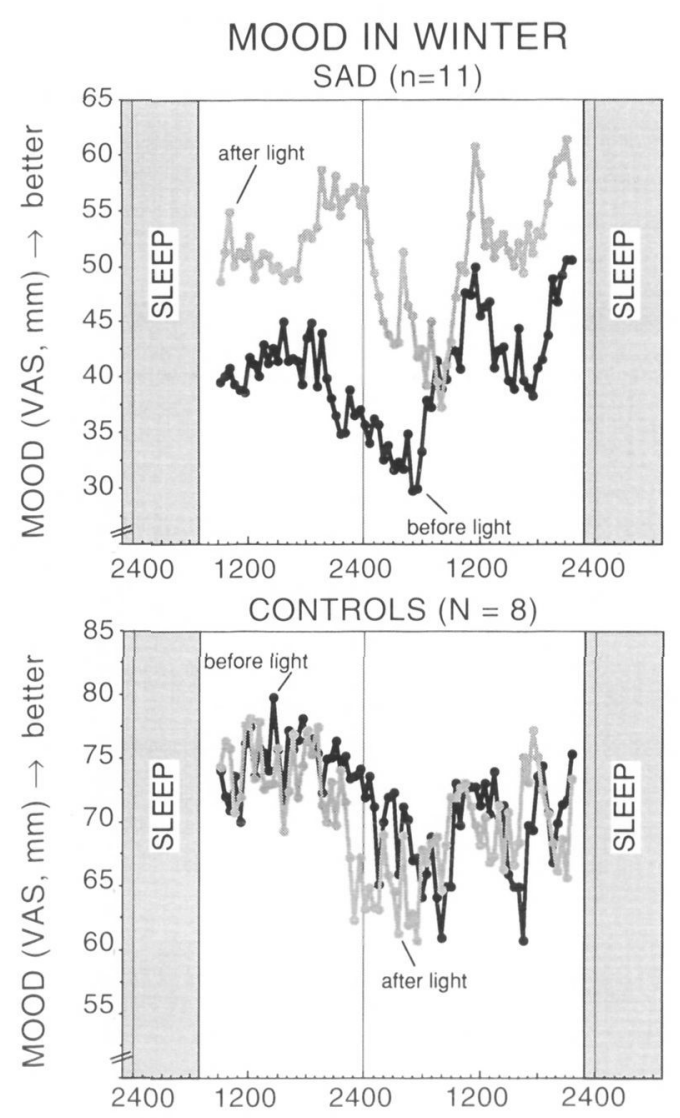

Figure 1. Half-hourly VAS self-ratings of mood during the 40-hour constant routine in winter. SAD patients are depressed $(50 \mathrm{~mm}=$ euthymia) and switch out of their depression in the morning (6 a.m.) of the second day of sleep deprivation. After light treatment $(6000$ lux, 10-14 h, 5 days), their average mood is increased. Control subjects have higher mood ratings, but also show a circadian rhythm, which is not modified by light treatment. Note the afternoon dip of mood on the second day of the constant routine. The scales for SAD and controls are different to show the rhythms more clearly.

Figuur 1. Zelfbeoordelingen van stemming met behulp van een visual analog scale elk half uur gedurende de $\mathbf{4 0}$ uur van een constant routine in de winter. SAD patienten komen uit hun depressie op de ochtend $(6 \mathrm{a} . \mathrm{m}$.$) van de tweede dag met slaapdeprivatie (50 \mathrm{~mm}=$ normale stemming). Na lichtbehandeling (6000 lux, 10-14 h, 5 dagen) is de gemiddelde stemming verbeterd. Controle personen hebben hogere stemmingsscores waar ook een circadiaan ritme in zit, dat niet verandert door lichtbehandeling. Let op de daling van stemming in de middag van de tweede dag van de constant routine. De verticale schalen zijn verschillend voor de twee figuren om de ritmes duidelijker te laten zien.

The morning mid-range crossing of temperature rise was significantly delayed in SAD patients compared with controls (by $81^{\prime}$ ). Only in SAD patients did light treatment significantly phase advance certain parameters of the temperature rhythm: the $24-\mathrm{h}$ component by $61 \pm 20^{\prime}$ $(\mathrm{p}<0.02)$, the circadian maximum by $108 \pm 26^{\prime}$ ( $\mathrm{p}<0.005)$, and the mid-range crossings - morning by $68 \pm 24^{\prime}(\mathrm{p}<0.02)$, evening by $41 \pm 14^{\prime}(\mathrm{p}<0.005)$.

\section{Salivary melatonin}

The melatonin rhythm has also been validated as hand of the biological clock in the CR. ${ }^{9}$ Amplitude, phase, and duration of melatonin secretion were similar in SAD patients and controls, and were not modified by light (e.g. melatonin onset and nocturnal duration, table I).

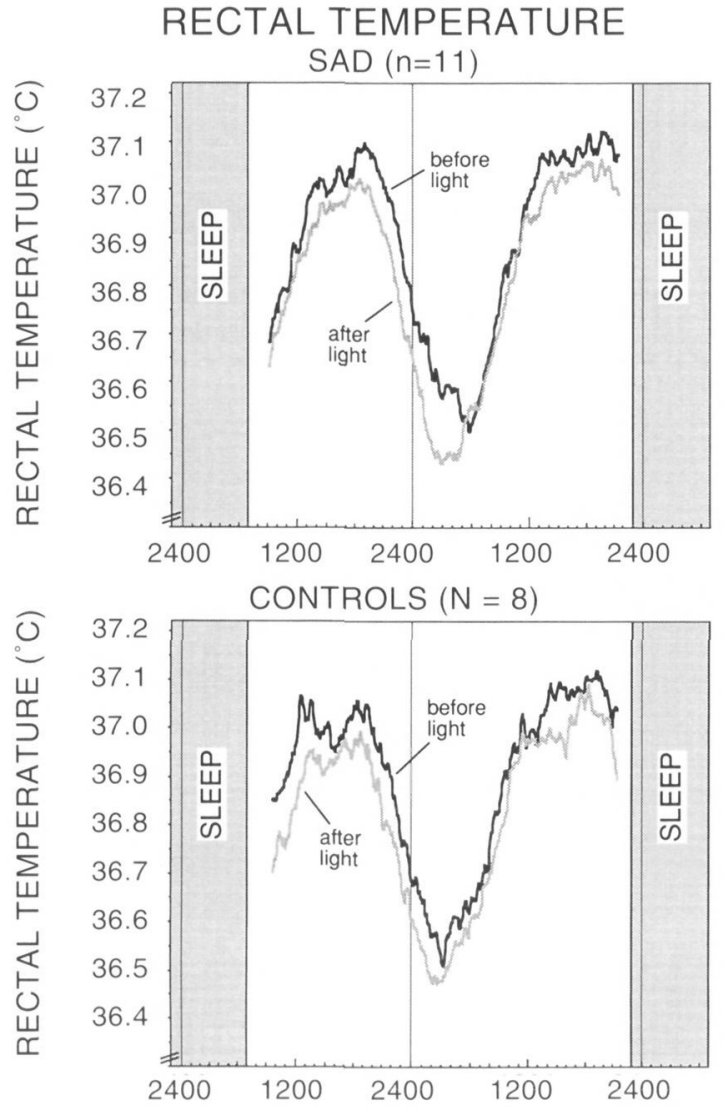

Figure 2

Circadian rhythms of rectal temperature during the 40-hour constant routine in winter. The timing of the minimum in SAD patients tends to be later than in controls, and significantly advances after light treatment. The amplitude in SAD is surprisingly robust. In both groups, light induces a small but significant decrease in temperature $\left(-0.07^{\circ} \mathrm{C}\right)$.

\section{Figuur 2}

Circadiane ritmen van lichaamstemperatuur gdurende de 40 uur van een constant routine in de winter. Het minimum in de curve van de SAD patiënten lijkt wat later te komen dan bij de controles, en het verschuift significant naar voren na lichtbehandeling. De amplitude van het ritme bij de SAD patiënten is opvallend constant. In beide groepen verlaagt de lichtbehandeling de temperatuur significant $\left(-0,07^{\circ} \mathrm{C}\right)$.

\section{Sleep EEG and sleep regulation}

Sleep EEG parameters were not disturbed in winter SAD. ${ }^{10-13}$ Recovery sleep after the sleep deprivation of the CR showed the well-known regulatory responses of sleep stage parameters and of the EEG power spectrum under all seasonal and light treatment conditions. Irrespective of diagnosis, midday light treatment induced some improvement in sleep (sleep latency and efficiency, REM sleep). In SAD patients, but not in controls, light treatment slightly increased EEG power density in the delta and theta frequencies. 
Table I.

Tabel I.

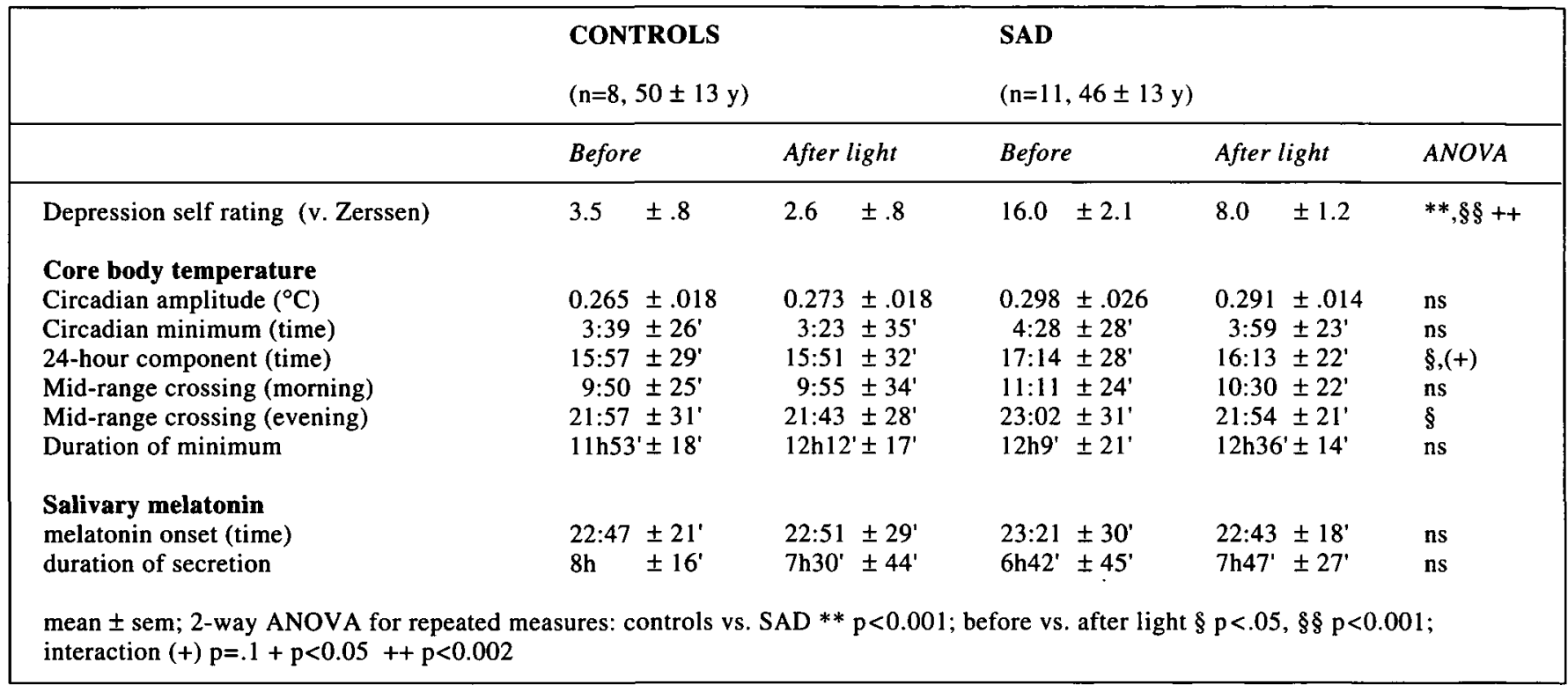

\section{CONCLUSIONS}

This CR study provides evidence that:

- SAD patients improve during sleep deprivation (as do patients with other depressive syndromes), but show a more robust improvement after light treatment.

- Certain parameters of the circadian temperature rhythm are phase-delayed in SAD patients and phase advanced by light treatment.

- The melatonin rhythm does not differ between SAD patients and controls, nor is it significantly modified by light treatment.

- The circadian amplitude of both temperature and melatonin rhythms is normal in SAD patients, and is not modified by light treatment.

- There is no difference between SAD patients and controls in the nocturnal duration of the temperature minimum or melatonin secretion.

- There is no abnormality of process ' $S$ ' as measured by the EEG power density in the delta frequencies in SAD patients; the small effects of light on sleep parameters are unlikely to mediate the antidepressant effect.

Analysis of further parameters measured in this study are necessary to support the statement that there appears to be no abnormality of process ' $C$ ' or of process ' $S$ ' in SAD patients that can explain their recurrent winter depression and the antidepressant effect of midday light.

\section{LITERATURE}

1. Rosenthal NE, Sack DA, Gillin JC, Lewy AJ, Goodwin FK, Davenport Y, Mueller PS, Newsome DA, Wehr TA. Seasonal affective disorder: a description of the syndrome and preliminary findings with light therapy. Arch gen Psychiat 1984; 41 : 72-80.

2. Wirz-Justice A. Biological rhythms in mood disorders. In: Bloom FE, Kupfer DJ, eds. Psychopharmacology. The Fourth Generation of Progress. New York: Raven Press 1994: 999-1017.

3. Daan S, Beersma DGM, Borbély AA. Timing of human sleep: recovery process gated by a circadian pacemaker. Am J Physiol 1984; 246: R161-R178.

4. Czeisler CA, Brown EN, Ronda JM, Kronauer RE, Richardson GS, Freitag WO. A clinical method to assess the endogenous circadian phase (ECP) of the deep circadian oscillator in man. Sleep Res 1985; 14: 295

5. Haug H-J, Wirz-Justice A, Kräuchi K, Graw P, Hetsch C, Leonhardt G, Brunner DP. Circadian rhythms of mood under a constant routine. Neuropsychopharmacology 1994; 10 (suppl): 235S.

6. Boivin DB, Duffy JF, Dijk D-J, Smith JA, Czeisler CA. Endogenous circadian rhythm of subjective modd in healthy young men. Society for Research on Biological Rhythms. 1994; 4: abstract \#110.

7. Wirz-Justice A, Kräuchi K, Graw P, Arendt J, English J, Brunner DP, Haug H-J, Leonhardt G. Testing circadian rhythm hypotheses of winter depression in the constant routine protocol. Neuropsychopharmacology 1994; 10 (Suppl): 51.

8. Wirz-Justice A, Kräuchi K, Graw P, Arendt J, English J, Haug HJ, Leonhardt G, Brunner DP. Are circadian rhythms involved in the pathophysiology of SAD and its treatment by light. Society for Research on Biological Rhythms 1994; 4: abstract \#107.

9. Shanahan TL, Czeisler CA. Light exposure induces equivalent phase shifts of the endogenous circadian rhythms of circulating plasma melatonin and core body temperature in men. J clin Endocrinol Metab 1991; 73: 227-235.

10. Brunner DP, Kräuchi K, Leonhardt G, Graw P, Wirz-Justice A Sleep parameters in SAD: effects of midday light, season, and sleep deprivation. Sleep Res 1993; 22: 396.

11. Brunner DP, Leonhardt G, Kräuchi K, Graw P, Wirz-Justice A. Homeostatic regulation of non-REM sleep in SAD is preserved across depressive episodes and seasons. Sleep Res 1993; 22: 325.

12. Brunner DP, Kräuchi K, Leonhardt G, Graw P, Wirz-Justice A. Sleep stage parameters in middle-aged women: effects of season, sleep deprivation, and midday light. Sleep Res 1994; 23: 481.

13. Brunner DP, Kräuchi K, Dijk D-J, Leonhardt G, Wirz-Justice A. Sleep EEG in winter depressed and healthy women: the effects of total sleep deprivation and midday light treatment. Biol Psychiat 1995; submitted. 

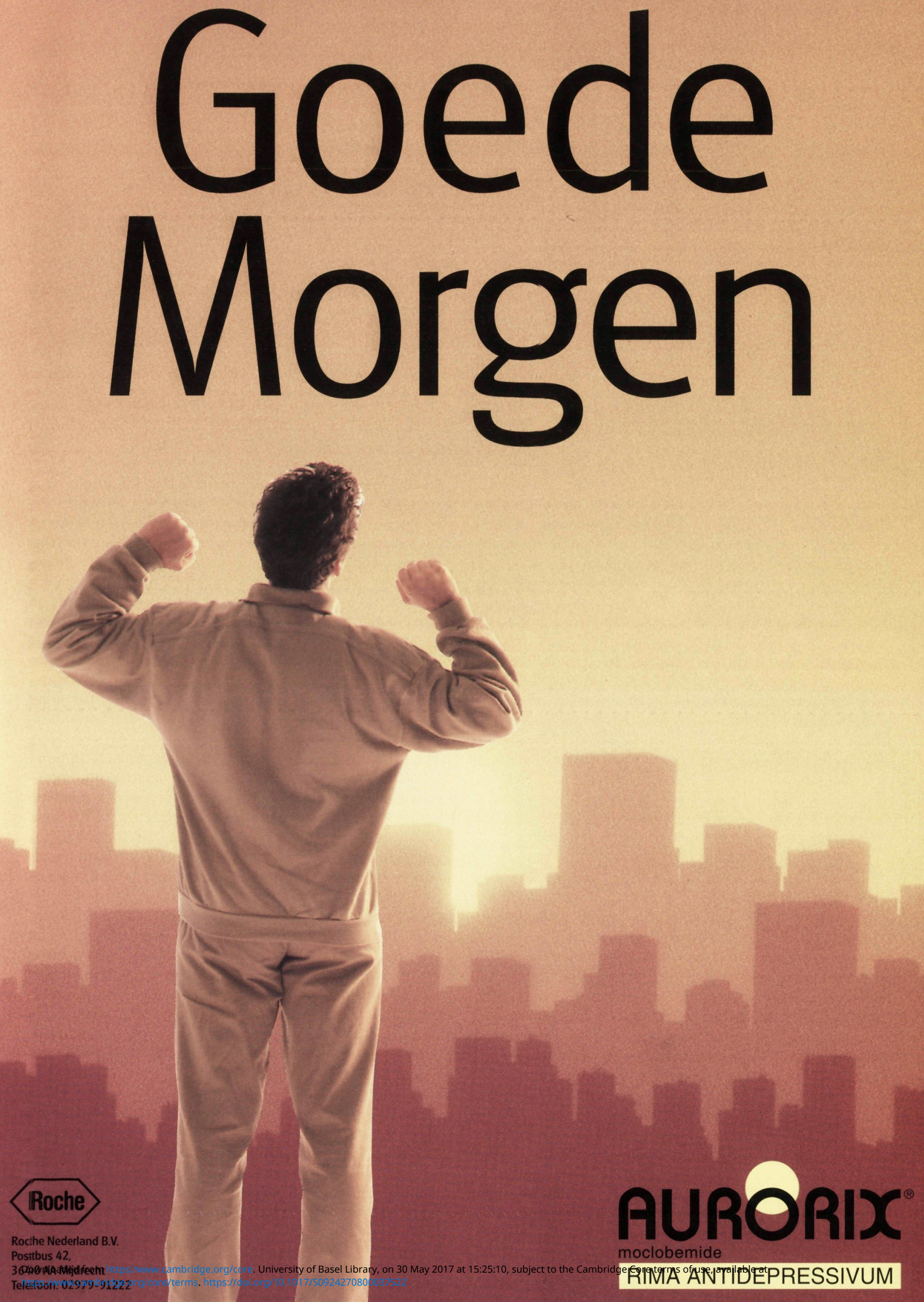